\title{
The New Marine Biological Research Station of the Bergen Museum.
}

For close upon one hundred years researches regarding marine fauna have been a prominent part of the work carried out by the Bergen Museum. The first biological station in Norway was built in the year of I89I and was attached to the museum. On account, however, of the expansion of the city of Bergen, the pollution of the salt-water supply for the station gradually increased to such an extent that the biological work there had to be abandoned.

By the generosity of private donors, who realised that the fine traditions of the maritime research work carried out at Bergen should be maintained, the Trustees of the Bergen Museum have been enabled to build a new station. The biological station (Fig. I) is now situated on the island of Herdla, about seventeen miles from Bergen. The station is thus right in the centre of one of the richest and most promising fields for research of the west coast of Norway, well known also through the

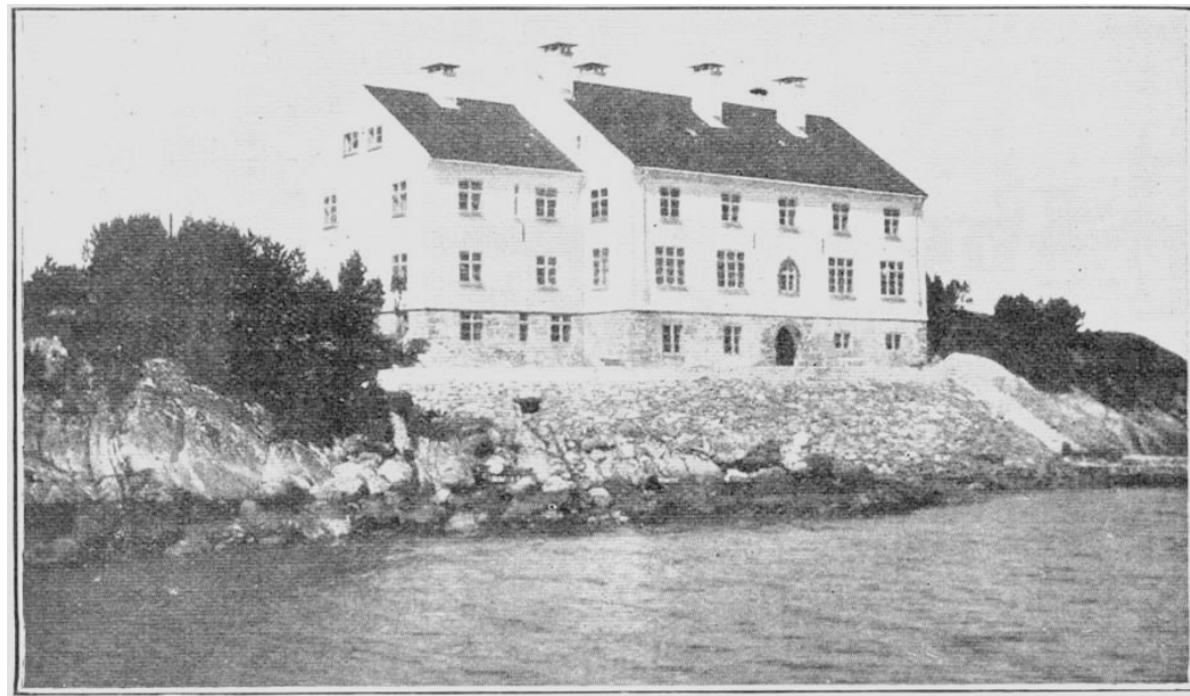

FIG. I.-Marine Biological Station at Herrlia, seen from the fjord.

investigations of such British naturalists as Norman, Jeffreys, Harmer, Punnett, and others. The open sea, the deep fjords, and the narrow sounds with their strong currents, offer here the most varied and changing conditions of life for marine fauna, which accordingly is extraordinarily rich and well represented.

Any biological condition typical of the west coast of Norway may be reached within less than two hours' sail from the station. The salt-water supply is taken from a depth of approximately 25 metres, which guarantees salt water of excellent quality and without appreciable changes in temperature and salinity. Thus are present the best conditions for experimental and embryological research.

The object of the station is to serve as a basis for scientific investigations, as well as for the international courses in marine biology which were held at the Bergen Museum for a number of years until I9r4, and with a large participation from abroad. The station is open to naturalists of all nations. During the period in the summer when no courses are held, the station has tables for ten scientific workers besides the staff. During the winter there are tables for five only. Being situated close to the open sea, which never freezes, the station can be kept open all the year round, and thus offers good opportunities for collecting material during the winter months. The station contains the necessary accommodation for housing naturalists visiting it.

A 25-ton research vessel, the Herman Friele, is attached to the station, and is equipped with appliances for research down to a depth of $I_{500}$ metres. Moreover, the station is provided with a smaller open motor boat and various rowing-boats.

By the opening up of this new station, facilities are afforded for utilising again the particularly favourable conditions for marine biological investigation offered by the west coast of Norway. I shall be glad to reply to any inquiries regarding the station or the reservation of tables.

A. BRINKMANN.

Museet, Bergen, Norway.

(Director.)

\section{Industrial Applications of the Microscope.}

WHILE one reads with satisfaction in NATURE of February 17, p. 239 , of the ever-increasing examples of the application of the microscope to industry, the fact remains that the use of the mineralogical microscope with the small amount of knowledge of crystal optics necessary has up to the present been practically disregarded.

In I9r8 a considerable amount of work was done in this connexion dealing particularly with explosives, but the results were never published, and hence it is thought that the following example may be of interest.

It was proved quite definitely at the Ardeer Factory of Nobel's Explosives Company that the degree of nitration in guncotton and nitrocellulose could be ascertained directly by the optical properties of the product. Thus it was found that the birefringence of ordinary cotton fibre before nitration was strong and of a positive character. The same cotton after being fully nitrated showed strong birefringence but of a negative character, while cotton with an intermediate degree of nitration was shown to be practically isotropic.

It was found afterwards that a corresponding work had been carried out by Dr. Phil Hans Ambron in Germany, and he published a table giving the actual values and character of the birefringence of nitrated cellulose and also nitrated ramie or China grass. It is, of course, true that the degree of nitration can be obtained quicker and more accurately by means of a nitrometer, but the two lots of information differ widely. The nitrometer gives the average nitration of the whole sample while the microscope gives the actual nitration of separate fibres, and is therefore a valuable test of the homogeneity of the sample.

During the War, when acetone was unobtainable a substitute had to be found as a solvent for nitrated cellulose in the making of cordite. Ether-alcohol was the substitute used. Now, while cellulose and almost any form of nitrated cellulose are soluble in acetone, ether-alcohol will only dissolve nitrated cellulose of a certain percentage nitration, and the homogeneous nitration of large samples of cotton was

NO. 2785 , VOL. I I I 7 